\title{
Influence of Nano-Silica in Al6061 Composites on Mechanical and Material Properties prepared through Powder Metallurgy
}

Naveenkumar Votarikari ( $\sim$ votarinaveen@gmail.com )

GIT: GITAM Institute of Technology https://orcid.org/0000-0001-6926-7123

N. Kishore Nath

DRDO Advanced Systems Laboratory

Poosa Ramesh Babu

Osmania University University College of Engineering

\section{Research Article}

Keywords: Al6061, nano-silica, powder metallurgy, and mechanical characterization, Orowan strengthening mechanism.

Posted Date: April 21st, 2021

DOl: https://doi.org/10.21203/rs.3.rs-423744/v1

License: (c) (i) This work is licensed under a Creative Commons Attribution 4.0 International License. Read Full License 


\section{Abstract}

The influence of composites preparation methods in the aerospace industry has evolved quite new challenges achieving better and desired properties. In this context, this work deals with the preparation of nano silica-based composite through the powder metallurgy technique. The composites prepared were tested for material characterization with morphological, X-Ray diffraction, and mechanical characterization with hardness, tensile strength, density, and porosity tests. The results revealed that the nano-silica has interfacial interaction with aluminum alloy. The strength of Al6061 nano-silica composite has the effect of sintering and compaction processes. Crystallization of Al6061 composite has been influenced by sintering time for nano-silica reinforcement. A compound was formed during the ball milling process during the blending of Al6061 and nano-silica powders was examined and detailed through material characterization. It revealed the structure as a mesoporous structure which created a route for better-impregnated bearing material. Al6061 nano-silica impregnated bearing with porous structure holds the lubricating fluid which is serving the purpose of self-lubrication and self-cooling by dissipating the heat generated during the running conditions. The strengthening mechanism like the Orowan effect and dislocation density strengthening enhanced the process and revealed the effect on nano-silica content. The wettability of silica was improved through binder in PM and the preheating process of powders. Hardness incremented up to $21 \%$ of base alloy through the PM technique.

\section{Highlights:}

- Nano silica has influence in Al6061 alloy by achieving compressive and wear resistant material for bearing applications.

- Powder metallurgy was adopted as best dispersive technique for nano silica reinforcement in aluminum alloy.

- The composite formed has the possibility of getting mesoporous structure with remarkable strength which is suitable for impregnated bearings in automobile applications.

- Mechanical and material characterization were carried out to test the properties for suitable applications.

\section{Introduction:}

Lightweight and durable materials in aerospace especially in bearing material applications have gained importance in ceramic-filled aluminum powder metallurgy composites [1, 2]. In this aspect, aluminum composites were used in wear-resistant materials with the addition of nano-silica as ceramic reinforcement to bear the load of sliding and compression parameters [3]. In imparting the wear and mechanical strength researchers have focused on the selection of reinforcing materials like alumina, silicon carbide, aluminum nitride, and boron carbide were frequent filler materials. Al6061 Composites have gained importance in obtaining desired properties in terms of mechanical, thermal, and wear characteristics, however with limitation of agglomeration and optimum addition of reinforcement into 
Al6061 matrix [4-8]. Silica is also abundantly available, durable, and high strength ceramic material which has the highest binding properties and strength enhancement properties in the aluminum matrix [9, 10]. Researchers have focused on gaining mechanical properties with the addition of $\mathrm{Al}_{2} \mathrm{O}_{3}$ to $10 \mathrm{wt} \%$ [11]. Rahimian et.al., research reveals the sintering temperature and time behavior and its influence on $\mathrm{Al}$ alloys with nano alumina as reinforcement. Process control agent was used for the preparation of composites with the limitation of the inert atmosphere $[1,12]$. Special techniques were adopted in achieving the desired properties and strength of composite materials like equal channel angular pressing (ECAP). Powder compaction has gained its densification of alumina reinforcement followed by the extrusion process [11]. Reinforcement powders were coated with nickel to gain green strength using an electroless method [3].

Production parameters in powder compaction and sintering process were gained in wear resistance at $440 \mathrm{MPa}$ pressure in uniaxial type. The sintering temperature at $600^{\circ} \mathrm{C}$ and $550^{\circ} \mathrm{C}$ has improved the hardness of Al-alumina composites [13]. In situ process was adopted and achieved the wear resistance to the composite prepared for $\mathrm{Al} 356$ and $\mathrm{SiC}$ particulate reinforcement. Powders were injected into the crucible during the casting process with an inert atmosphere [3]. Improved mechanical properties were observed with SiC particles into Al6061 composite with powder mixing method followed by hot extrusion process with limitation of milling time and sintering time. Hybrid composites were used in imparting wear resistance to Al7075-alumina-graphite powders [14]. From the literature aspect, it concluded that the addition of hard ceramic particles into the Al matrix has gained properties with variable parameters of sintering time, temperature, relative density, and type of reinforcement.

In this present work, the Preparation of Al6061 and nano-silica composites using powder blending, compaction, and sintering processes were investigated. Dispersion and optimal addition of nano-silica reinforcement in Al6061 affected the hardness, wear resistance properties. A compound formed during the powder mixing process revealed the structure as a mesoporous structure which created a route for better-impregnated bearing material [10]. Al6061 nano-silica impregnated bearing with porous structure holds the lubricating fluid which is serving the purpose of self-lubrication and self-cooling by dissipating the heat generated during the running conditions. $[15,16]$ Composites were analyzed with theoretical strengthening techniques. Elastic modulus was tested on a tensile test process using UTM. Hardness and porosity were correlated with the dispersion and optimum addition of nano-silica particles. Morphological and X-ray diffraction studies were carried out to test the material properties and its behavior.

\section{Experimental:}

\section{Materials}

Al6061 powder with 150 mesh size was procured from Famous Chemical Industries, Hyderabad. Nanosilica with 300-350nm size in amorphous form was used, which was supplied from nano-wings chemicals. Die wall lubricant was used as zinc stearate and binder sodium silicate was also supplied from Famous Chemical Industries, Hyderabad, Telangana, India [10]. 
Table 1

Composition of samples

\begin{tabular}{|ll|}
\hline Sample Name & Composition \\
\hline AlSi-0 & Pure Al6061 \\
\hline AlSi-1 & Al6061 $+1 w t \%$ nano silica \\
\hline AlSi-3 & Al6061+3wt\% nano silica \\
\hline AlSi-5 & Al6061 $+5 w t \%$ nano silica \\
\hline AlSi-7 & Al6061 $+7 w t \%$ nano silica \\
\hline AlSi-10 & Al6061+10wt\% nano silica \\
\hline AlSi-12 & Al6061 $+12 w t \%$ nano silica \\
\hline AlSi-15 & Al6061 $+15 w t \%$ nano silica \\
\hline
\end{tabular}

Preparation of Composite: The method adopted was powder metallurgy, in which both the Al6061 and nano-silica were taken in powder form. Powders were blended with a ball milling set up as shown in Fig. 2. Sodium silicate was taken as a binder for powder for blending in the ball milling setup. Blending was carried out for $1 \mathrm{hr}$ at $150 \mathrm{rpm}$ with a ball to powder ratio of 10:1. The blended powder was filled in to die cavity with die wall lubricate as zinc stearate. This mechanical alloying was carried out with no atmospheric control. The powder was uniaxially compacted at the $150 \mathrm{~T}$ universal testing machine (UTM). Compaction pressure was maintained at 300MPa for a better densification process at room temperature. The sample was removed from the die with the same uniaxial system by reversing the die in the UTM machine. A similar process followed for Al6061 powders without the addition of nano-silica to find the effect of nano-silica particles on the mechanical alloying process, mechanical characterization, and strengthening mechanism for contrasting with prepared composite on various filler loading conditions. A similar procedure was followed for $1 \mathrm{wt} \%$, 3wt $\%, 5 w t \%, 7 w t \%, 10 w t \%, 12 w t \%$ and $15 w t \%$ for achieving optimum filler loading to achieve the maximum desired property. The detailed compositions for each composite were tabulated in Table 1. Followed by a sintering process at $550^{\circ} \mathrm{C}$ for $3 \mathrm{hrs}$ of duration. The determination of sintering time was carried out based on the trial and error basis starting from $450^{\circ} \mathrm{C}$ to $600^{\circ} \mathrm{C}$ with time is also variable beginning with $1 \mathrm{hr}$ to $5 \mathrm{hr}$. $[7,12,17,18]$. The sintering process was carried out in a muffle furnace without an inert atmosphere. Sintered samples were displayed in Fig. 5.

\section{Mechanical testing:}

\section{Elastic behavior:}

The compaction was carried out using UTM under uniaxial loading conditions. From the sample, tensile strength behavior was derived from the empirical relationship[19, 20]. Compression strength was carried 
out till the samples compressed to mid portion of height. Two different dies were utilized to match with ASTM standards for elastic modulus testing and for the flexural testing process. For testing of densification and porosity the same samples were used. The prepared samples were shown in Fig. 10.

\section{Densification and Porosity:}

Density and porosity were carried out as per ASTM B328. The principle of Archimedes was used for finding the density of powder composites with water as a medium. The weighing was carried out using an electronic weighing machine of samples before and after dipping them into the water. Relative and sintered densities were also carried out to find the porous volume before and after the sintering process.

\section{Hardness:}

Brinnel's hardness measurement was carried out with loading of $30 \mathrm{Kg}-\mathrm{f}$ with a round indenter of $2.5 \mathrm{~mm}$ diameter. The experiment was performed at five locations of sample to have average value and to avoid errors. This averaging avoided the locations where only nano silica or Al6061 is present, as it is intended to do the testing on mixtures of Al6061 and nano silica.

\section{Morphological studies and X-Ray Diffraction:}

Scanning electron microscopy was used for morphological analysis on broken samples of the flexural test at the middle of the portion to find out the dispersion and behavior of nano-silica in the composite, which was shown in Fig. 1. An average of 5 locations was taken for each composition of nano-silica for morphology tests. XRD test ware also carried out on broken specimens of compression tests. The samples were tested for investigating the nano-silica particles interacting with the Al6061 base matrix.

\section{Flexural rigidity:}

Three-point bending test was utilized to find the flexural strength on samples as per ASTM. An average of five samples was used for avoiding the error in the measurement system. Flexural behavior was also related to the bending and tensile strength of the composite, which was strengthened by the mechanism of Orowan and dislocation theories.

\section{Results And Discussion:}

Preparation of composite: The preparation of samples was carried out using planetary ball milling set up for the purpose of uniform mixing of Al6061 and nano-silica powders. The set speed and time only regulated the proper mixing by avoiding formation residual stresses. The coincidence of powder rotation speeds and less amount time led to form a different compound as shown in Figure 3. A possible cause is the uneven rotation speed of the ball mill. The reasons behind the compound formation were analyzed with XRD and morphological studies. (i) The mesoporous structure formed with oxygen content in nanosilica. (ii) The pre-sintering process was carried out during the ball milling process to form a strong structure. (iii) Uncrystallized compounds were formed with porous structure leading to mesoporous structure $[10,13,17]$.

\section{Elastic behavior:}


Yield strength of Al-nano silica composite was increasing up to $10 \mathrm{wt} \%$ of nano silica content as represented graphically in Figure 6, this was due to the presence of lesser parts of silica content leads to enhance the strength and obstructing crack propagation by powder particles of Al6061 and nano silica. This obstructing phenomenon is due to Orowan strengthening mechanism. On the other hand, at higher silica content of beyond 10wt\% nano silica content, the same silica particles make the ductile Al6061 matrix to brittle matrix by weakening bonds of Al6061 and nano silica powders. This trend was also strengthened by XRD and SEM graphs, which were represented in Figure 1 \& Figure 7. Compressive strength of Al-Si composites was increasing till $12 \mathrm{wt} \%$ of sample, as powders have highest compressibility at axial loads under UTM as shown in figure 4 . At the mid portion of sample in height, the Al-Si composite was in stable metal form but in bulged shape, beyond that the samples started breaking.

The incremental percentage of compressive strength of AlSi-12 is $182 \%$ compared to AlSi-0 composite as shown in figure 12. The similar trend of yield strength with AISi-10 is $92 \%$ compared to AlSi-0 composite as shown in figure 6 . The incremental values of compressive and yield strength were correlating to the behavior of brittle. It was also evident that the basic nature of Al6061 ductile was not lost by retaining the high compressive strength. This high compressive strength is suitable for bearing applications of Al6061nano silica composite. However, the addition of nano silica ceramic particles is limited to $10 \mathrm{wt} \%$ for optimum utilization.

\section{Densification and Porosity:}

Powder's densities were calculated before and after the sintering process. Relative and sintered densities were represented in figure 8 and figure 9 , respectively. The values showed the incremental percentage at AlSi-10 for relative density of $1.5 \%$, whereas for sintered density at AISi-12 of $11 \%$ growth compared with AlSi-0 composite. The incremental values were also due to following reasons: (i) The Al6061 particles mesh size and nano silica mesh size forms the solid solution strengthening due to interstitial movement of atoms during the sintering process. (ii) Sintering temperature of $550^{\circ} \mathrm{C}$ for all samples at a period of 3hrs was created enough period to relieve the stresses generated during the ball milling process and those were filled by nano silica particles. (iii) The ratio of nano silica particles also has an effect in filling porousness created during the pre-sintering process of powders. (iv) The pre-sintering process was carried out to match thermal equilibrium of nano silica particles and Al6061 particles, however the process of pre sintering also increased the reaction time for the oxidation process of Al6061 [15,16,21]. The Porosity in the Al6061 and nano silica powders were allowed as it is intended for applications with impregnated bearings.

\section{Hardness:}

The hardness of AlSi-12 was incremental at a percentage of 21 compared with AlSi-0 composite. The sacrificial yield strength of $8 \%$ for AlSi-10 was not remarkable with gain of hardness value to $21 \%$ when compared with AISi-0 composite were represented in figure 11. This was also due to the presence of hard and brittle particles of nano silica content [9,22-24]. The presence of nano silica particles in the soft matrix of Al6061 created the hard and strong bonds. The movement of grains were obstructed by the 
nano silica particles at pressed locations. The average of 5 locations were taken for measurement, where the dislocation of grains was found to be hard. The reasons behind the better hardness values are (i) Dislocations of grains on the top surface is obstructing by the nano silica particles, (ii) The hard and brittle grains were formed on the surface during sintering process, (iii) The sintering process was also created heat treatment environment for Al6061 nano silica samples [25-27].

\section{Morphological studies and X-Ray Diffraction:}

The images of samples also reveal the clusters and aggregation of nano silica particles, which were mentioned in Figure 1. In Figure 1(a) The white particles represent the presence of nano silica particles [28]. The images were captured on broken specimens of flexural test, the behavior crack was quite evident from the boundaries of white regions of nano silica particles. Sintering time was also found to be a major influencing factor in achieving the crystallinity of the composite $[9,29]$. The reasons for agglomeration of particles is due to (i) with incremental values of nano silica particles, the similar behavior materials were cohesively attracted in turn formed the clusters of nano silica particles, (ii) The wettability of Al6061 and at AlSi-12wt\% nano silica particles during ball milling process was created the agglomerations, though movement of tungsten carbide balls in milling process, (iii) More the wt\% of nano silica particles more the volume of nano silica particles, which is dominating the less volume content of Al6061 though at highest wt\% of Al6061, as reinforcements taken were in nano size [8,14].

Flexural rigidity: Fracture toughness value of composite was following the trend of incremental with percentage change of $28 \%$ for AlSi-12wt\% compared with Pure Al6061 samples were represented in figure 13. These incremental values were due to the fracture load bearing behavior of nano silica particles in the matrix of Al6061. Three point bending tests were performed based on a bending moment equation for rectangular specimens applying point loads at mid portion by creating reaction loads at opposite sides of Al6061-Silica composite. As the sample is a mixture of Al6061 and nano silica powders, less indentation was noticed on the loading side at mid portion whereas other surfaces were facing the tensile load. Powders are much elongated during the sintering process, the ductility behavior was quite low compared with the conventional casted piece $[30,31]$.

Strengthening Mechanism: Increasing the values of mechanical properties for Al6061 and nano silica composite was observed in experimental, and those values were theoretically analyzed with Orowan strengthening mechanism. The enhancement of properties was observed due to the obstruction of crack propagation under loading conditions [32-35]. The obstruction of crack was due to the grain refinement and dislocation movement during compaction and sintering process, it implies that Orowan mechanism has effect in this aspect. The improved values of sintered density at ALSi-12 of $11 \%$ growth compared with the AISi-0 composite was noted. The hardness of AISi-12 was incremental at a percentage of 21 compared with AISi-0 composite. The sacrificial yield strength of $8 \%$ for AlSi-10 was not remarkable with gain of hardness value to $21 \%$ when compared with AlSi-0 composite.

\section{Conclusion:}


Preparation of composite with nano silica reinforcement had increased marginal growth of mechanical properties. The challenge in obtaining the less agglomerated Al6061-nano silica composite was achieved to an extent with possible limitations. In this work the conclusions are made based on type of test that was performed and application that are intended for are as follows:

- Density and porosity values were increased due to following reasons: (i) The Al6061 particles mesh size and nano silica mesh size forms the solid solution strengthening due to interstitial movement of atoms during the sintering process. (ii) Sintering temperature of $550^{\circ} \mathrm{C}$ for all samples at a period of $3 \mathrm{hrs}$ was created enough period to relieve the stresses generated during the ball milling process and those were filled by nano silica particles. (iii) The ratio of nano silica particles also has an effect in filling porousness created during the pre-sintering process of powders. (iv) The pre sintering process was carried out to match thermal equilibrium of nano silica particles and Al6061 particles, however the process of pre sintering also increased the reaction time for the oxidation process of Al6061. The Porosity in the Al6061 and nano silica powders were allowed as it is intended for applications with impregnated bearings.

- The reasons behind the better hardness values are: (i) Dislocations of grains on the top surface is obstructing by the nano silica particles, (ii) The hard and brittle grains were formed on the surface during sintering process, (iii) The sintering process was also created heat treatment environment for Al6061 nano silica samples.

- The reasons behind the compound formation were analyzed with XRD and morphological studies are: (i) The mesoporous structure formed with oxygen content in nano-silica. (ii) The pre-sintering process was carried out during the ball milling process to form a strong structure. (iii) Uncrystallized compounds were formed with porous structure leading to mesoporous structure.

Finally, the addition of nano silica particles is found to be difficult though the incremental values are remarkable. Powder compaction process, sintering time and temperature were having the influence on strengthening and dislocation of particles in working condition of Al6061-nano silica sample.

\section{Declarations:}

\section{Funding statement}

This research received no specific grant from any funding agency

\section{Conflict of Interest}

No Potential conflict of interest was reported by the authors.

\section{Author contributions}

Votarikari Naveen Kumar: Conceptualization, Methodology, Experimentation, Result Analysis, WritingOriginal draft Preparation. 
N. Kishore Nath: Supervision.

Poosa Ramesh Babu: Supervision

Availability of data and material

All data generated or analyzed during this study are included in this article.

\section{Compliance with ethical standards}

The present study work was not conducted on human or experimental animals where national or international guidelines are used for the protection of human subjects and animal welfare.

\section{Consent to participate}

Not Applicable

\section{Consent for Publication}

I confirm that the manuscript has been read and approved by named and that there are no other persons who satisfied the criteria for authorship but are not listed. I further confirm that the authors listed in the manuscript have been approved.

\section{Acknowledgements}

The author would like to thank Dr. P. Eshwaraiah for providing facilities at GITAM Deemed to be University.

\section{Ethical Standards section}

\section{Disclosure of potential conflicts of interest:}

There are no potential conflicts of interest for this research work.

\section{Research involving Human Participants and/or Animals:}

No animals or humans were participated in this research work.

Informed consent: I confirm that the manuscript has been read and approved by named and that there are no other persons who satisfied the criteria for authorship but are not listed. I further confirm that the authors listed in the manuscript have been approved.

\section{References:}

1. Rahimian M, Ehsani N, Parvin N, Baharvandi HR (2009) The effect of sintering temperature and the amount of reinforcement on the properties of Al-Al2O3 composite. Materials Design 30(8):3333- 
2. RASHID N, HUSSAIN Z (2018) The Effect of Reinforcement Amount and Sintering Temperature on Mg Matrix Composite Fabricated by Powder Metallurgy. Int J Curr Res Sci Eng Technol 1(Spl-1):516

3. Amirkhanlou S, Niroumand B (2011) Development of Al356/SiCp cast composites by injection of SiCp containing composite powders. Materials Design 32(4):1895-1902

4. Moustafa SF, Abdel-Hamid Z, Abd-Elhay AM (2002) Copper matrix SiC and Al2O3 particulate composites by powder metallurgy technique. Mater Lett 53(4-5):244-249

5. Kabeel AE, Sathyamurthy R, Mageshbabu D, Madhu B, Anand P, Balakrishnan P (2020) Effect of mass flow rate on fresh water improvement from inclined PV panel basin solar still. Materials Today: Proceedings, 32, 374-378

6. Kang YC, Chan SLI (2004) Tensile properties of nanometric Al2O3 particulate-reinforced aluminum matrix composites. Mater Chem Phys 85(2-3):438-443

7. Fogagnolo JB, Robert MH, Torralba JM (2006) Mechanically alloyed AIN particle-reinforced Al-6061 matrix composites: Powder processing, consolidation and mechanical strength and hardness of the as-extruded materials. Materials Science Engineering: A 426(1-2):85-94

8. Şener Karabulut GU, Çinici $H$ (2016) Study on the mechanical and drilling properties of AA7039 composites reinforced with Al203/B4 C/SiC particles [J]. Composites Part B 93:43-55

9. Kumar VN, Nath K, N., \& Ramesh Babu P (2020) Effect of reinforcement and fabrication of Al6061 nanosilica composite prepared using single-and two-step methods. Advances in Materials and Processing Technologies, 1-20

10. Kumar VN, Chaitanya L (2017) Preparation and Characterization of Al6061 with Micro Silica MMC. Materials Today: Proceedings, 4(9), 9875-9878

11. Haghighi RD, Jahromi SJ, Moresedgh A, Khorshid MT (2012) A comparison between ECAP and conventional extrusion for consolidation of aluminum metal matrix composite. J Mater Eng Perform 21(9):1885-1892

12. Rahimian M, Ehsani N, Parvin N, reza Baharvandi $H$ (2009) The effect of particle size, sintering temperature and sintering time on the properties of Al-Al203 composites, made by powder metallurgy. J Mater Process Technol 209(14):5387-5393

13. Rahimian M, Parvin N, Ehsani N (2011) The effect of production parameters on microstructure and wear resistance of powder metallurgy Al-Al203 composite. Materials Design 32(2):1031-1038

14. Baradeswaran A, Perumal AE (2014) Wear and mechanical characteristics of Al 7075/graphite composites. Composites Part B: Engineering 56:472-476

15. Moghadam AD, Omrani E, Menezes PL, Rohatgi PK (2015) Mechanical and tribological properties of self-lubricating metal matrix nanocomposites reinforced by carbon nanotubes (CNTs) and graphene-a review. Composites Part B: Engineering 77:402-420

16. Omrani E, Rohatgi PK, Menezes PL (2017) Tribology and applications of self-lubricating materials. CRC Press 
17. Toptan F, Kerti I, Daglilar S, Sagin A, Hacioglu T (2011) Effect of Particle Size Particle Surface Modification Pressing Pressure and Sintering Temperature on Microstructure and Mechanical Properties P/M Al-B4C Composites. Supplemental Proceedings: Materials Processing and Energy Materials, 1, 491-498

18. Yilong D, Fei T, Kun Y (2015, August) Effect of SiC p particle size and anneal on properties of Al/SiC composites prepared by powder liquid-phase sintering. In 2015 16th International Conference on Electronic Packaging Technology (ICEPT) (pp. 347-353). IEEE

19. Ravichandran M, Sait AN, Anandakrishnan V (2014) Synthesis and forming behavior of aluminiumbased hybrid powder metallurgic composites. International Journal of Minerals Metallurgy Materials 21(2):181-189

20. Sharma A, Sagar S, Mahto RP, Sahoo B, Pal SK, Paul J (2018) Surface modification of Al6061 by graphene impregnation through a powder metallurgy assisted friction surfacing. Surface Coatings Technology 337:12-23

21. Karakoç $H$, Karabulut Ş, Çıtak R (2018) Study on mechanical and ballistic performances of boron carbide reinforced Al 6061 aluminum alloy produced by powder metallurgy. Composites Part B: Engineering 148:68-80

22. ATLA S, Kaujala PL (2020) Investigation of graphite effect on the mechanical and tribological properties of Al 7075-SiC-graphite hybrid metal matrix composites. Tribologia-Finnish Journal of Tribology, 37(1 - 2), 26-32

23. Kumar AK, Venkataramaiah P (2021) Experimental investigation on surface integrity of Inconel 718 under hot machining and optimisation of its process parameters. Advances in Materials and Processing Technologies, 1-13

24. Kumar VN, Nath NK, Babu PR (2021, February) Experimental investigation on sintering time of Al6061 based nano silica nano composite. In AIP Conference Proceedings (Vol. 2317, No. 1, p. 020018). AIP Publishing LLC

25. Chen B, Xi X, Gu T, Tan C, Song X (2020) Influence of heat treatment on microstructure evolution and mechanical properties of TiB2/Al 2024 composites fabricated by directed energy deposition. Journal of Materials Research Technology 9(6):14223-14236

26. Wang P, Gammer C, Brenne F, Niendorf T, Eckert J, Scudino S (2018) A heat treatable TiB2/Al-3.5 Cu$1.5 \mathrm{Mg}$-1Si composite fabricated by selective laser melting: microstructure, heat treatment and mechanical properties. Composites Part B: Engineering 147:162-168

27. Rajasekar M, Faizal UM, Sudhagar S, Vijayakumar P (2020) Influence of heat treatment on tribological behavior of $\mathrm{Al} / \mathrm{ZrO} 2 /$ fly ash hybrid composite. Materials Today: Proceedings

28. Kumar VN (2021) Effect of Surfactant on Swelling Behavior and Mechanical Characterization of NBR-Nano-Silica Nanocomposites. Silicon, pp 1-7

29. Karakoç H, Karabulut Ş, Çıtak R (2018) Study on mechanical and ballistic performances of boron carbide reinforced Al 6061 aluminum alloy produced by powder metallurgy. Composites Part B: Engineering 148:68-80 
30. LEE HH, KON M, ASAOKA K (1997) Influence of modification of $\mathrm{Na2O}$ in a glass matrix on the strength of leucite-containing porcelains. Dent Mater J 16(2):134-143

31. Raghuram KS, Vemireddi S, Alamanda SS (2019) Flexural Stress Analysis on Three-Point Bending of Aluminum Matrix Composite. In Recent Advances in Material Sciences (pp. 383-395). Springer, Singapore.32. Website. [cited 7 Apr 2021]. doi:10.1007/s12633-019-00338-8

32. Kumar CR, Malarvannan RRR, JaiGanesh V (2020) Role of SiC on Mechanical, Tribological and Thermal Expansion Characteristics of B 4 C/Talc-Reinforced Al-6061 Hybrid Composite. Silicon 12(6):1491-1500

33. Amirkhanlou S, Rahimian M, Ketabchi M, Parvin N, Yaghinali P, Carreño F (2016) Strengthening mechanisms in nanostructured $\mathrm{Al} / \mathrm{SiC} \mathrm{p}$ composite manufactured by accumulative press bonding. Metall Mater Trans A 47(10):5136-5145

34. Borodianskiy K, Kossenko A, Zinigrad M (2013) Improvement of the mechanical properties of Al-Si alloys by TiC nanoparticles. Metall Mater Trans A 44(11):4948-4953

\section{Figures}




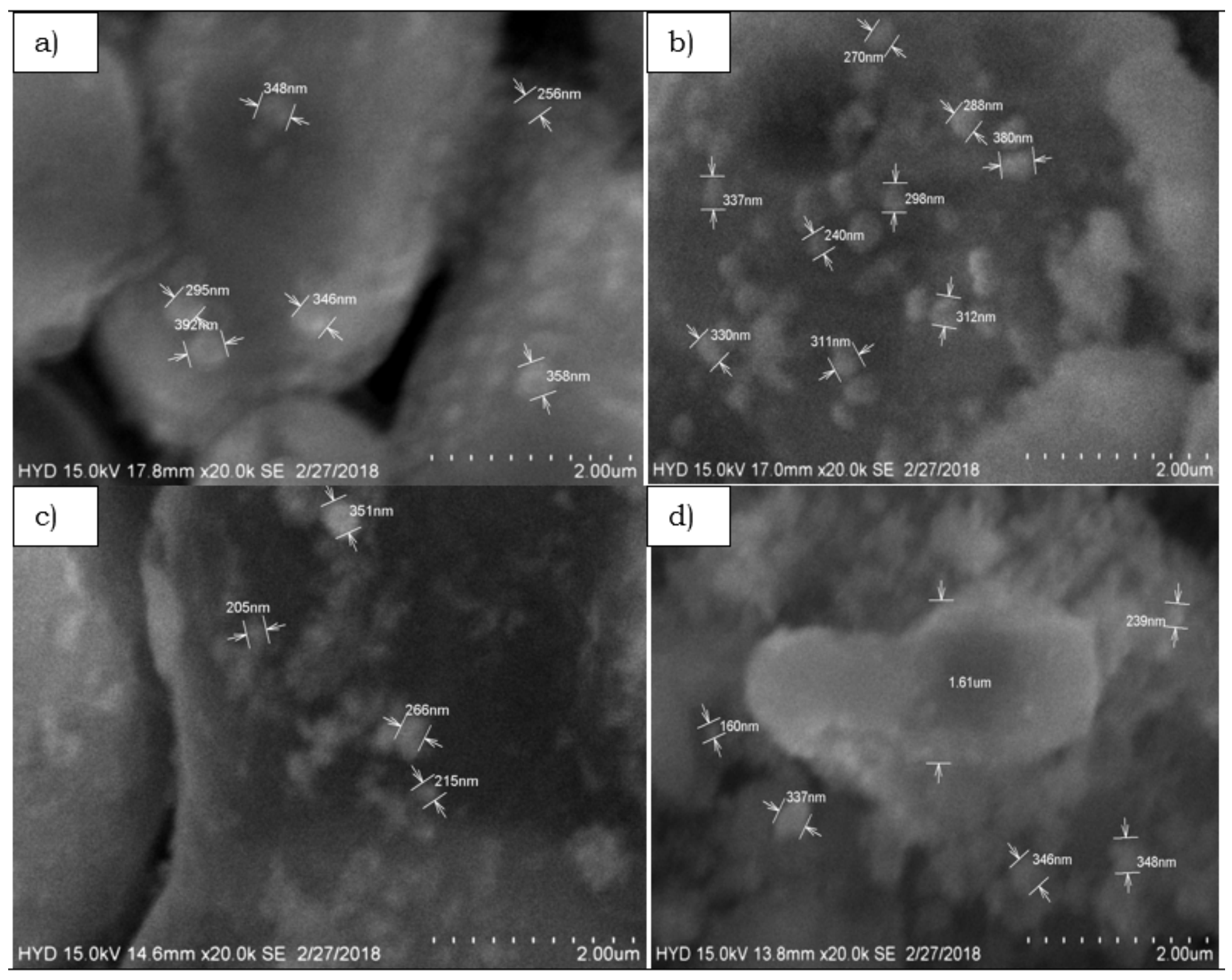

Figure 1

SEM micrographs of a)AISi-1 b)AISi-5, c)AISi-10 and d)AISi-12 

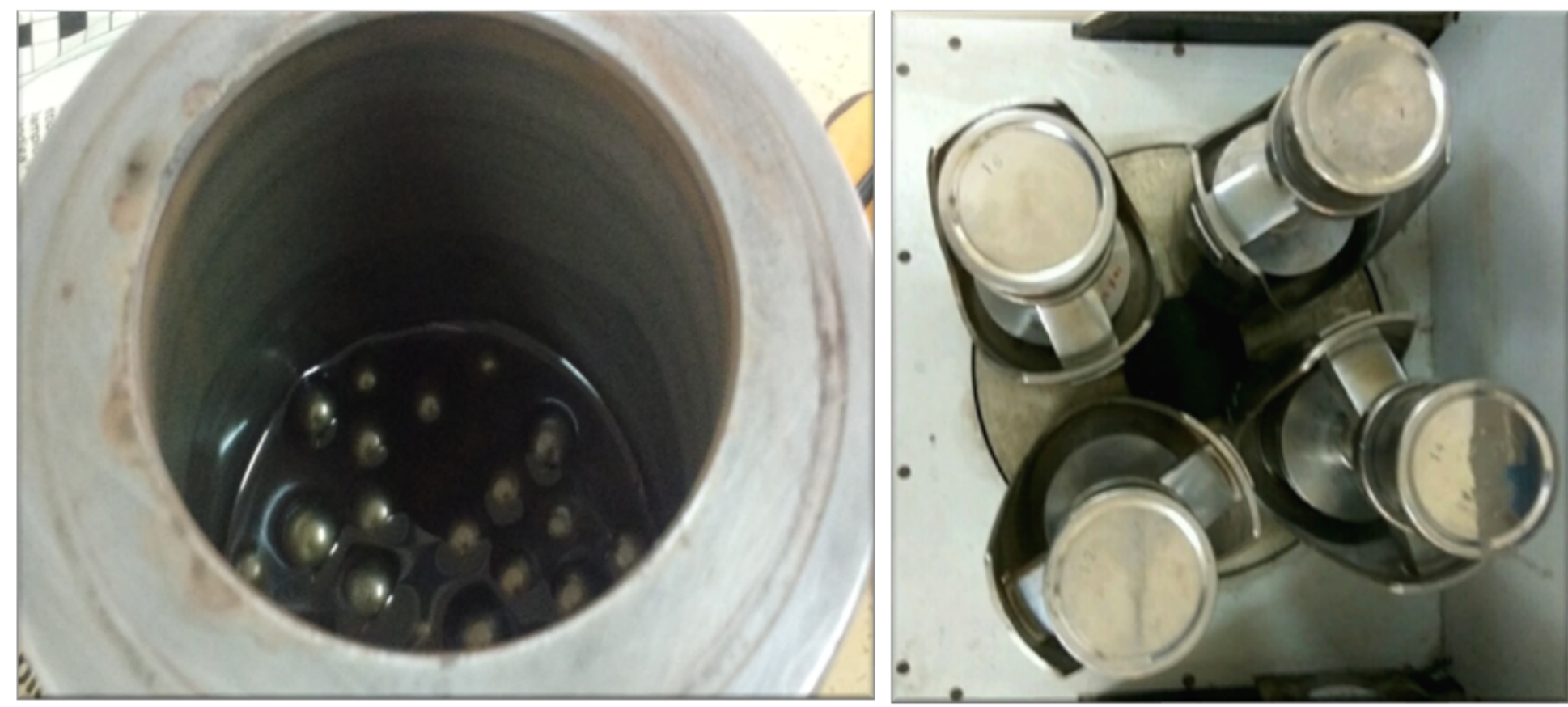

Figure 2

Ball milling set up with tungsten carbide balls and toluene

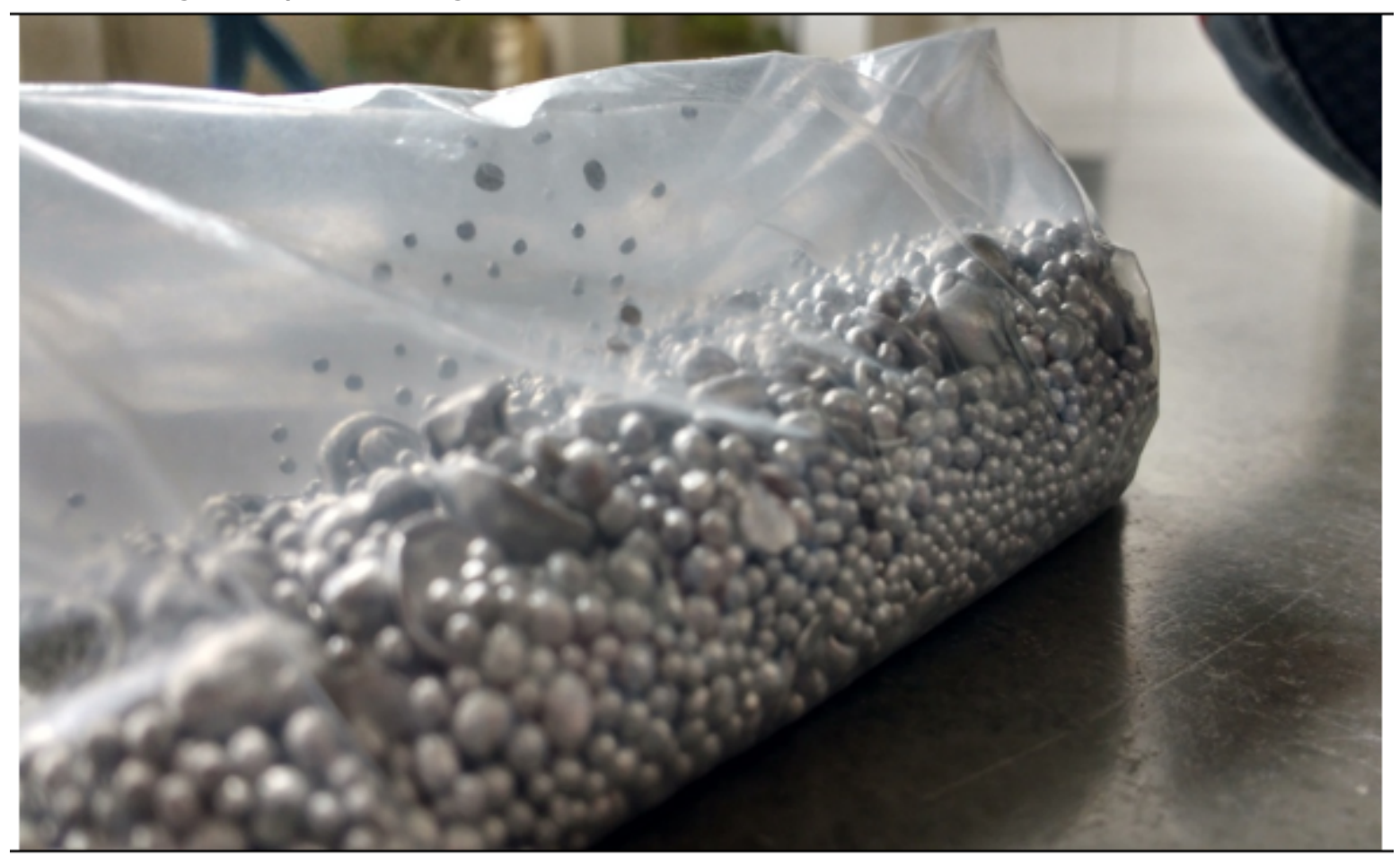

Figure 3

Coagulated Al composite with nano silica content of Al6061-Silica composite 


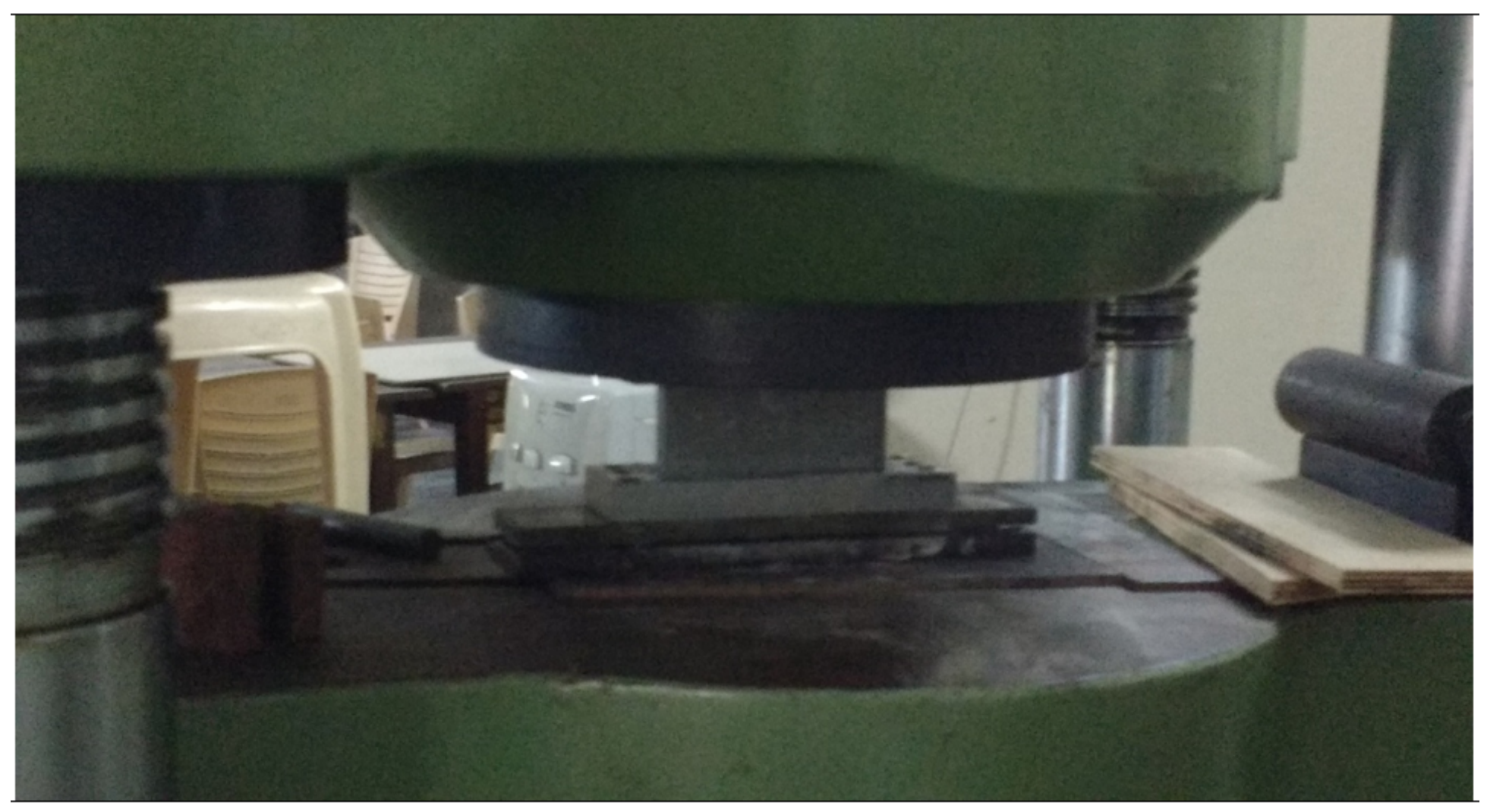

Figure 4

Compaction Process in UTM of Al6061-Silica composite

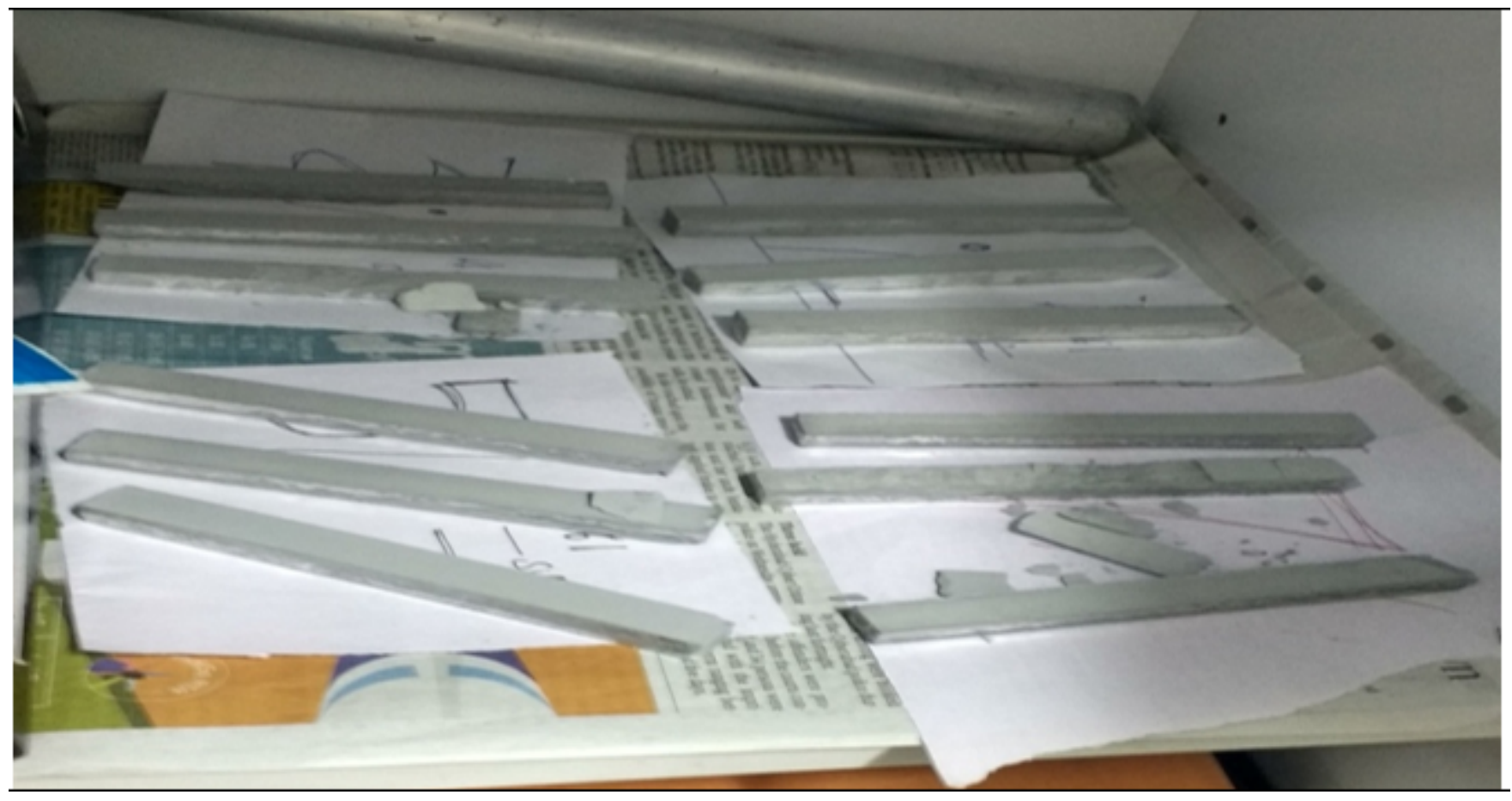

Figure 5

Sintered Samples of Al6061-Silica composite 


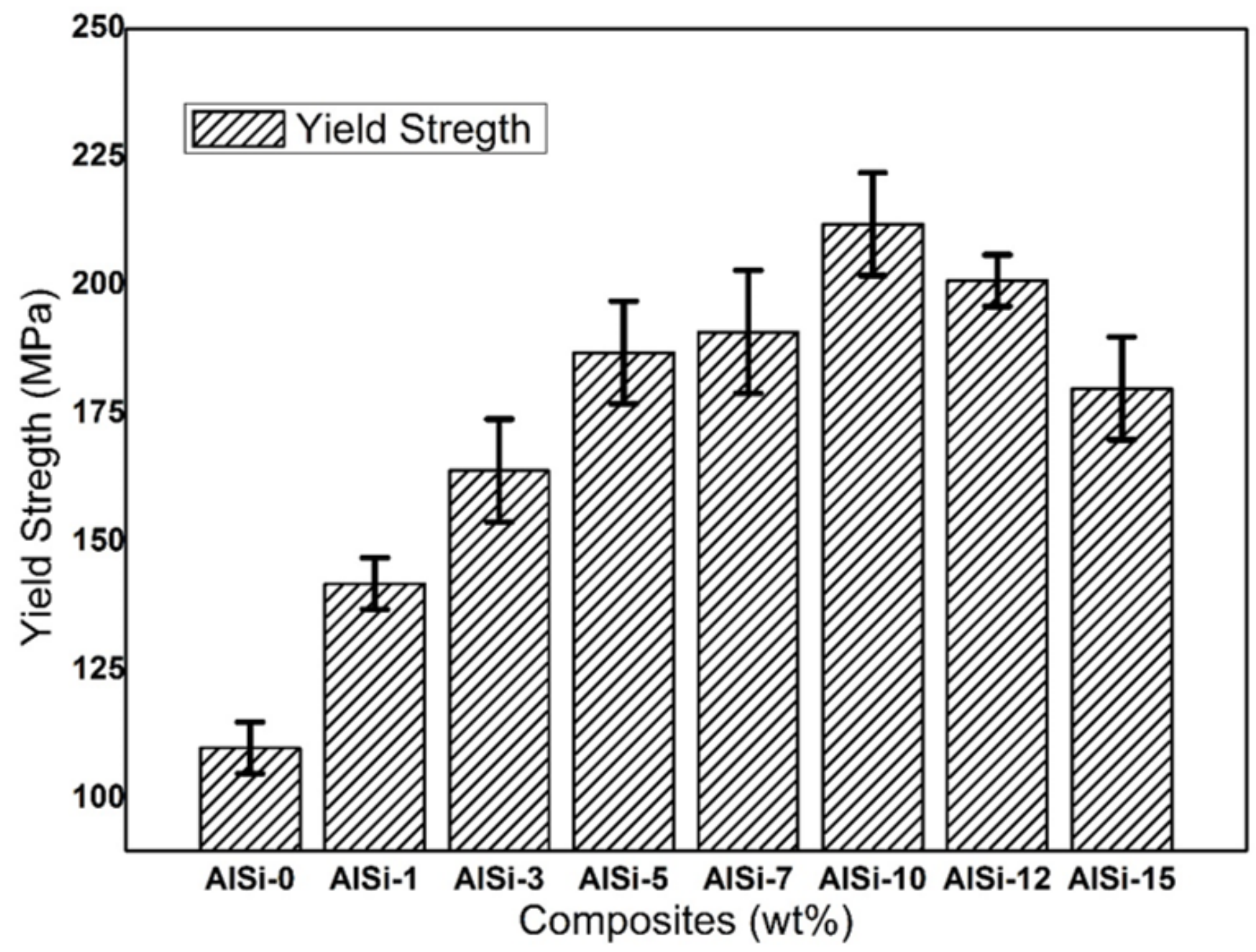

Figure 6

Yield Strength of Al6061-Silica composite 


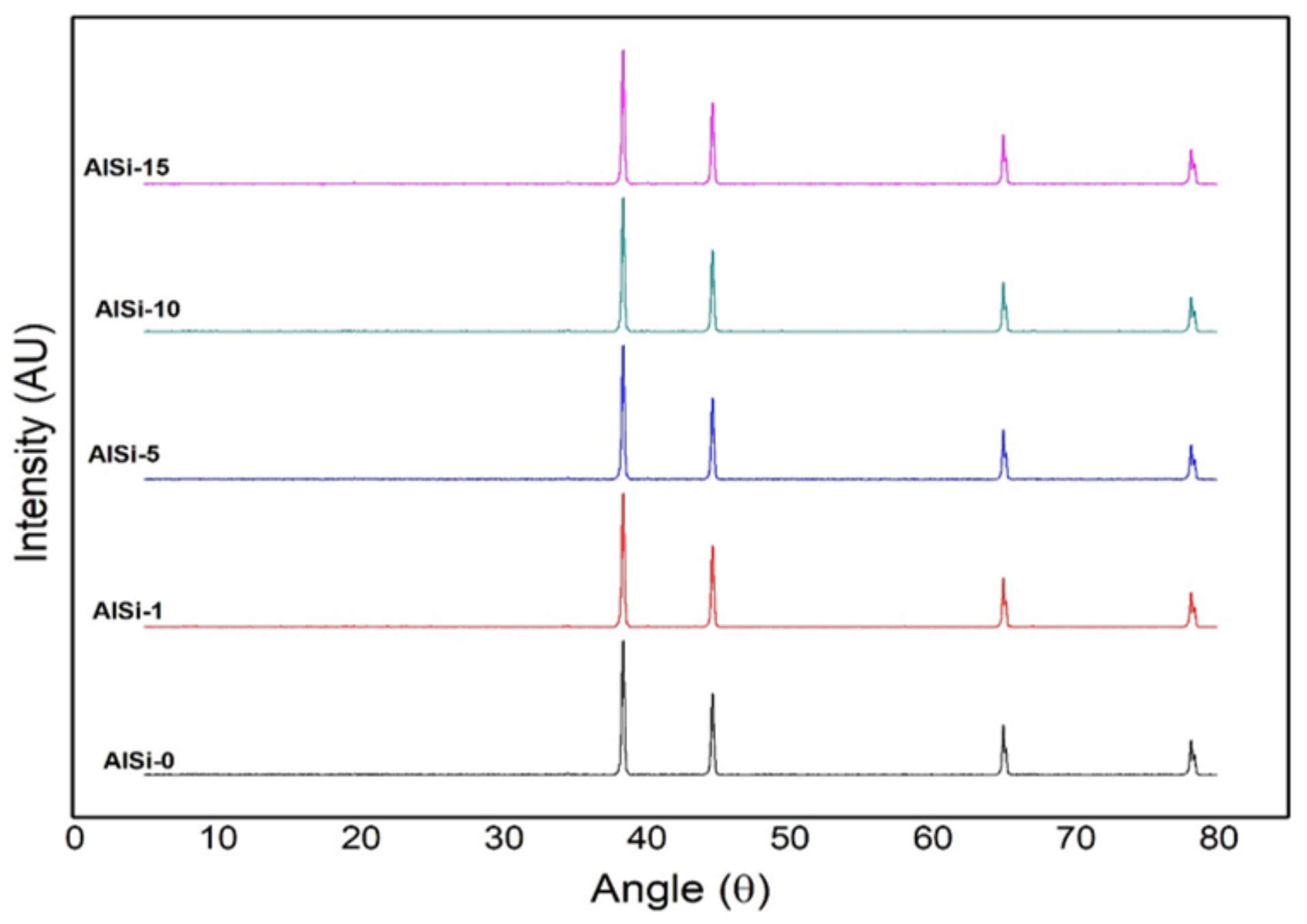

Figure 7

X-Ray Diffraction of Al6061-Silica composite 


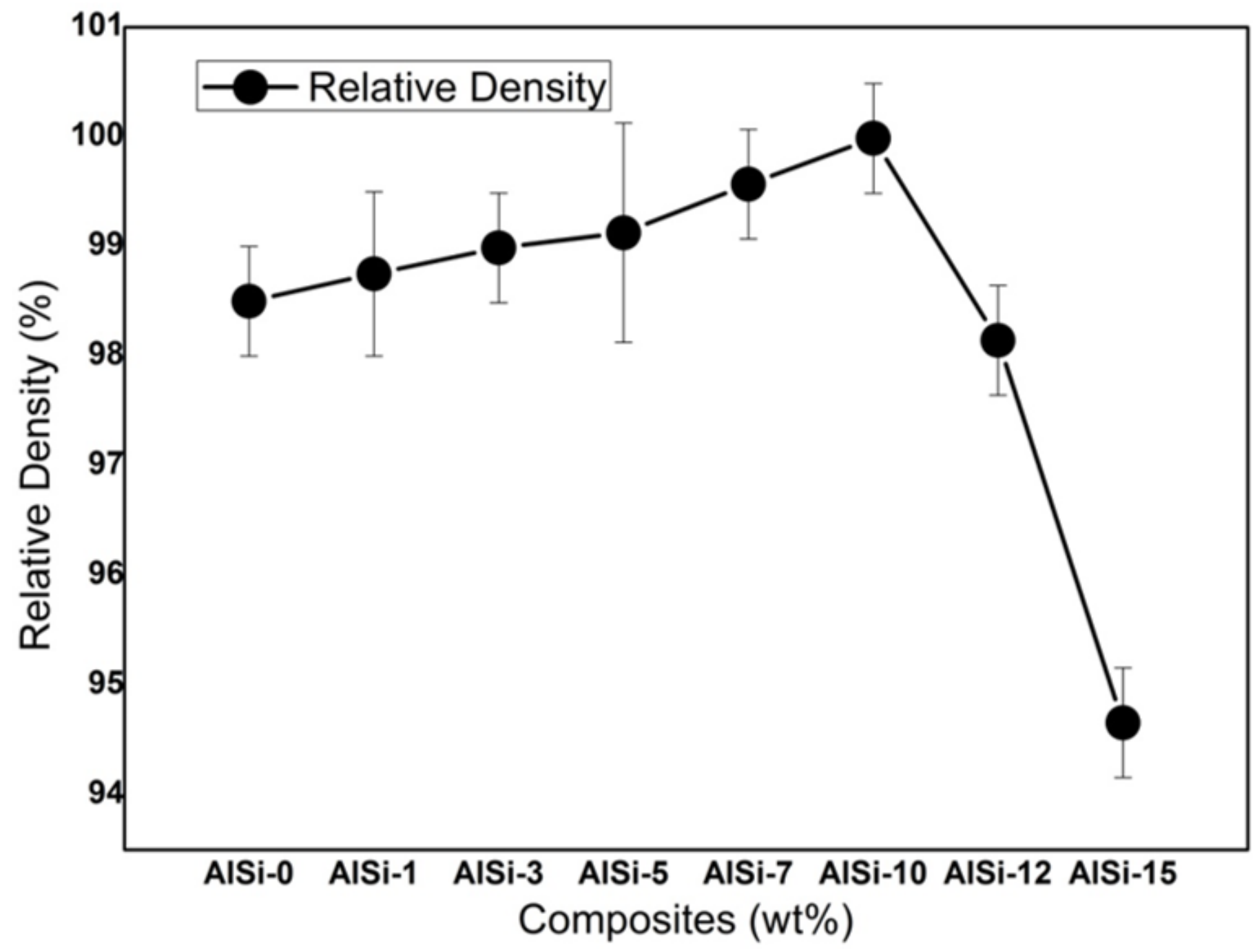

Figure 8

Relative density for compacted samples of Al6061-Silica composite 


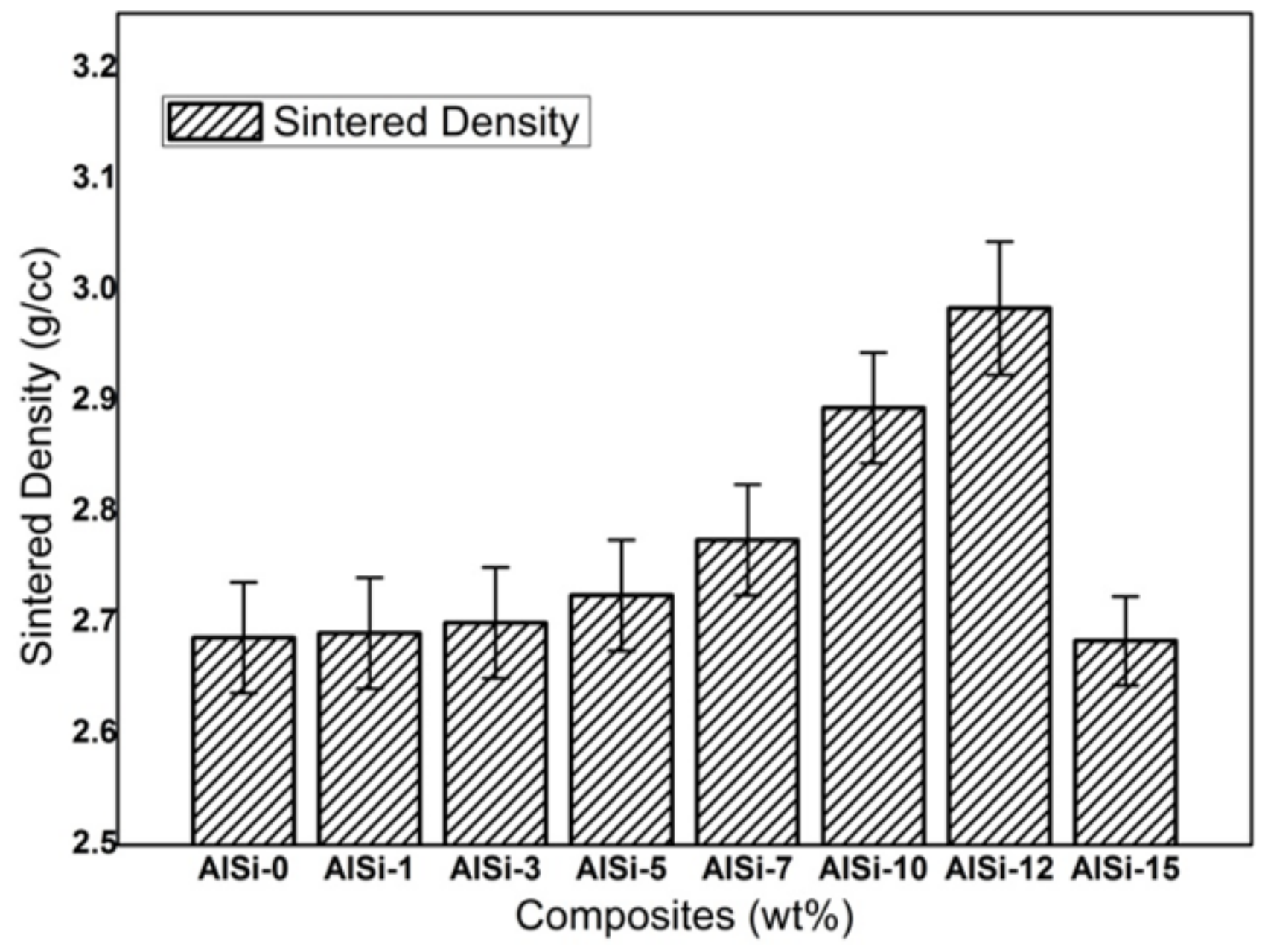

Figure 9

Sintered density of Al6061-Silica composite 


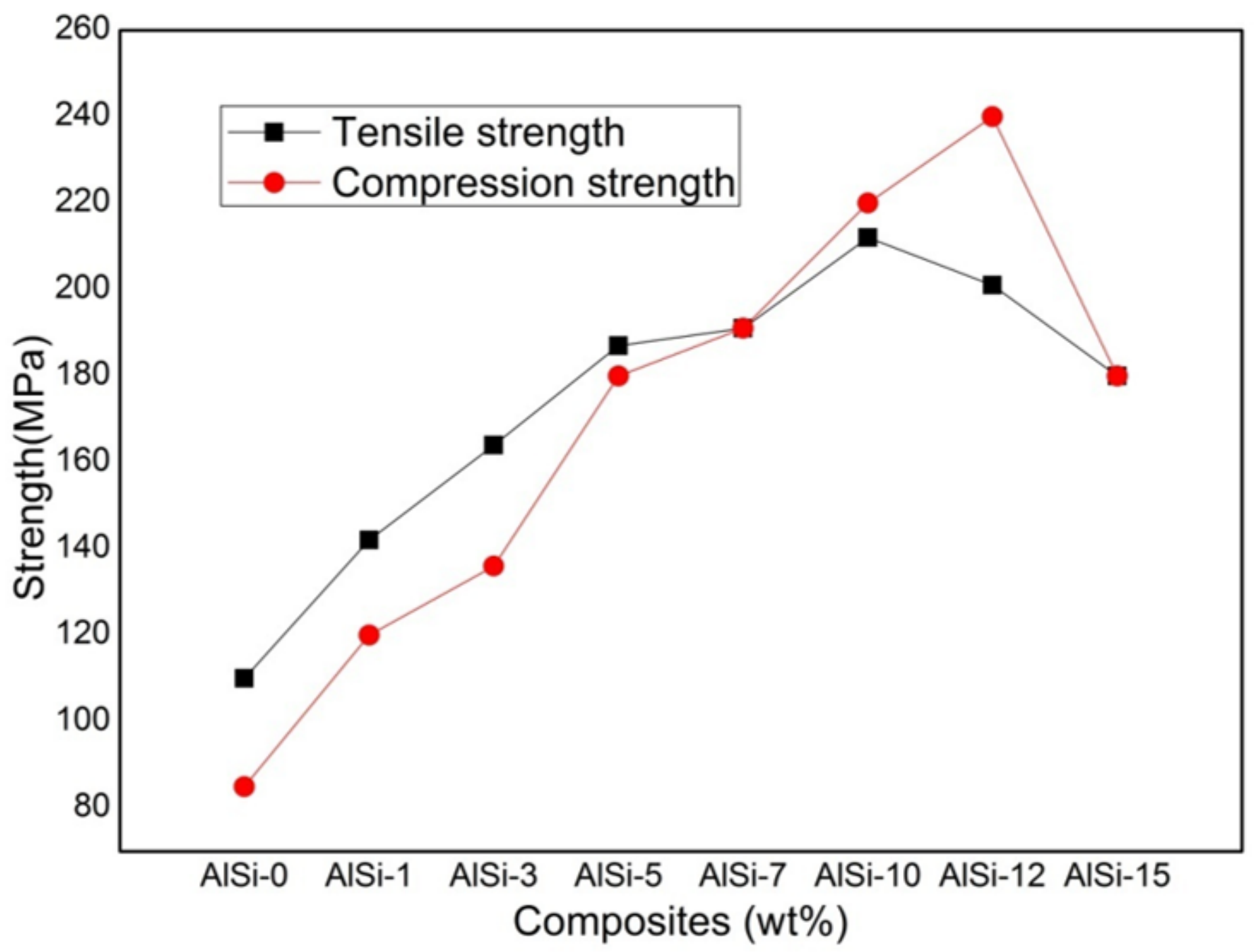

Figure 10

Tensile \& Compression strength of Al6061-Silica composite 


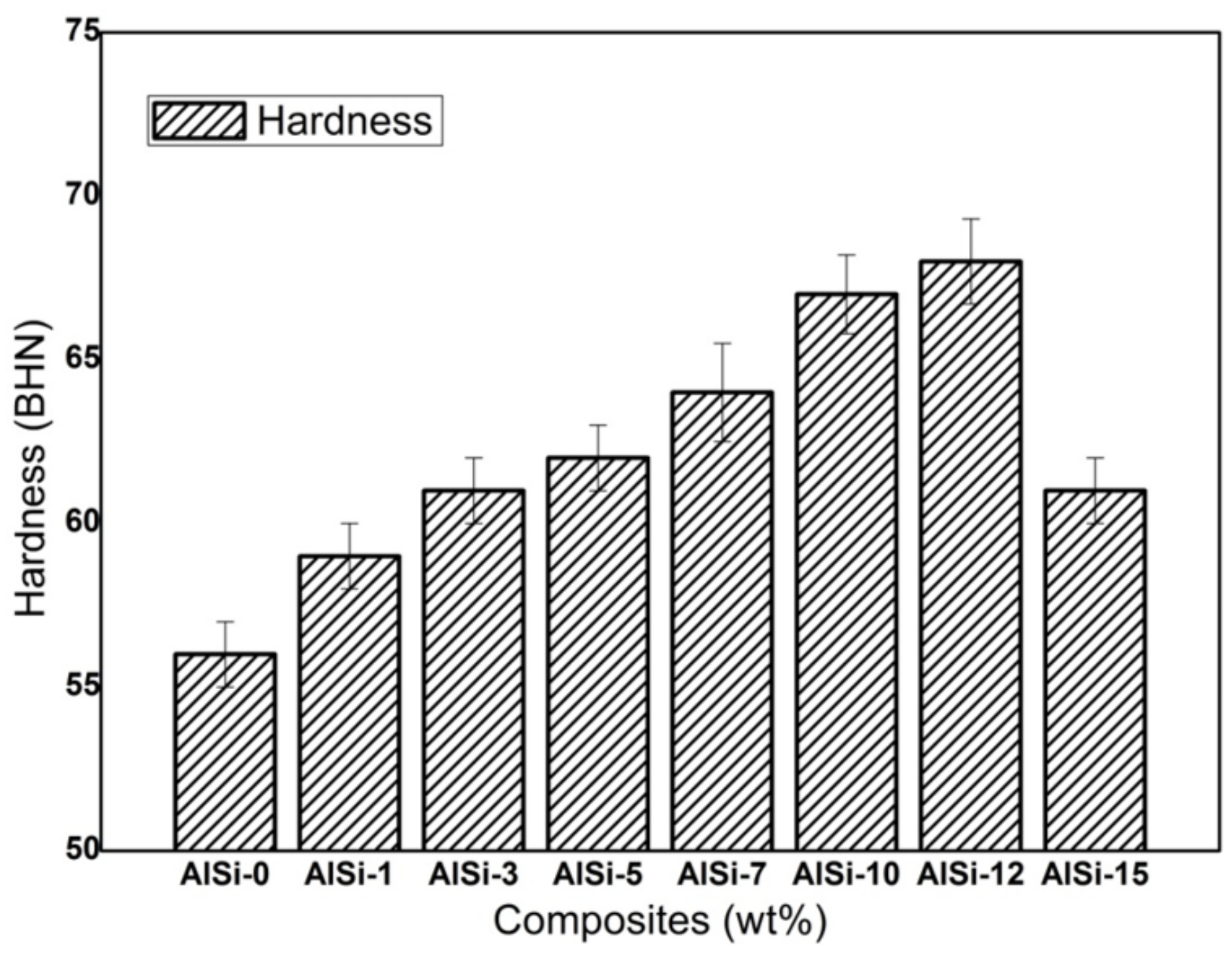

Figure 11

Hardness values of Al6061-Silica composite 


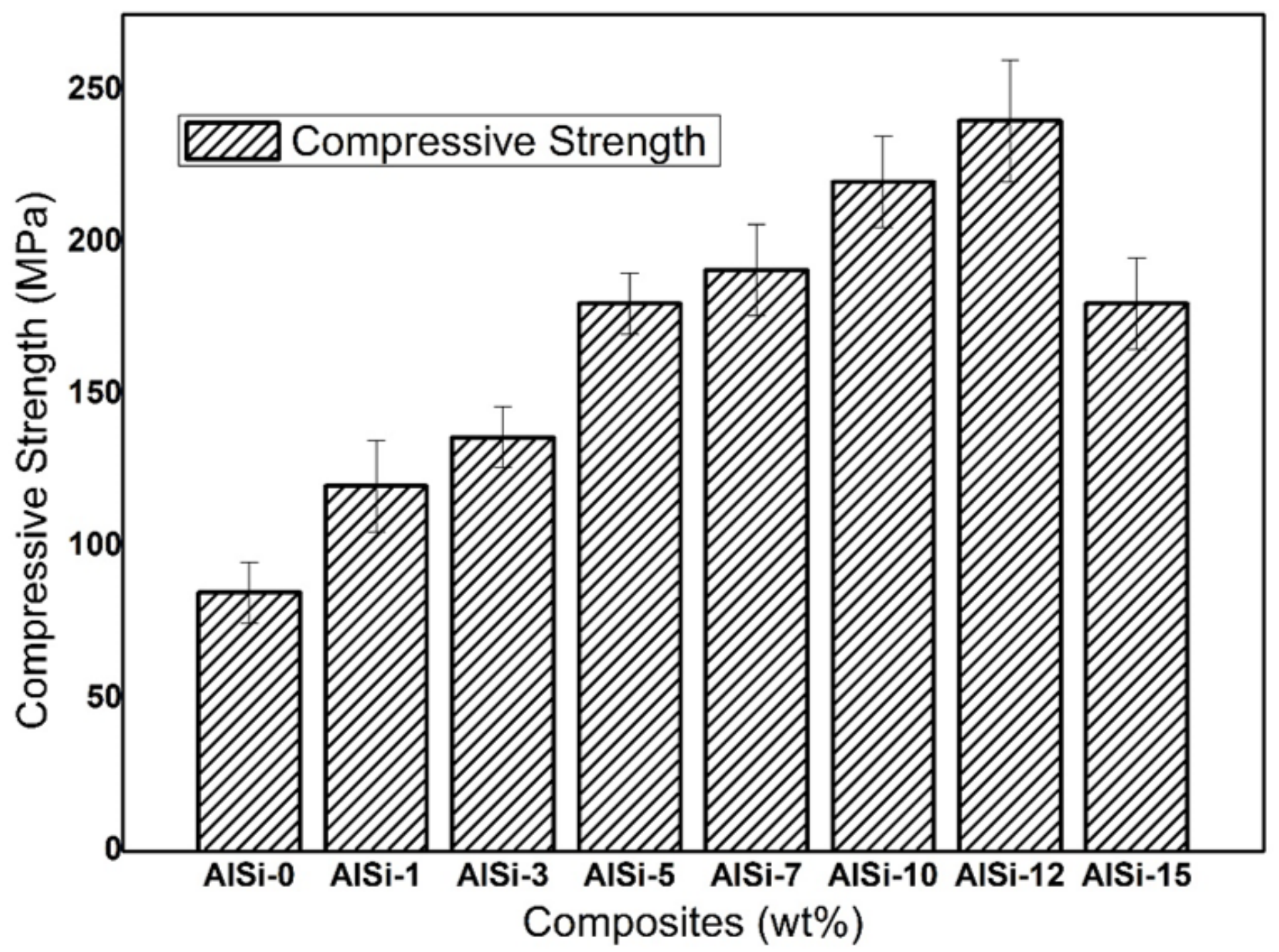

Figure 12

Compressive Strength of Al6061-Silica composite 


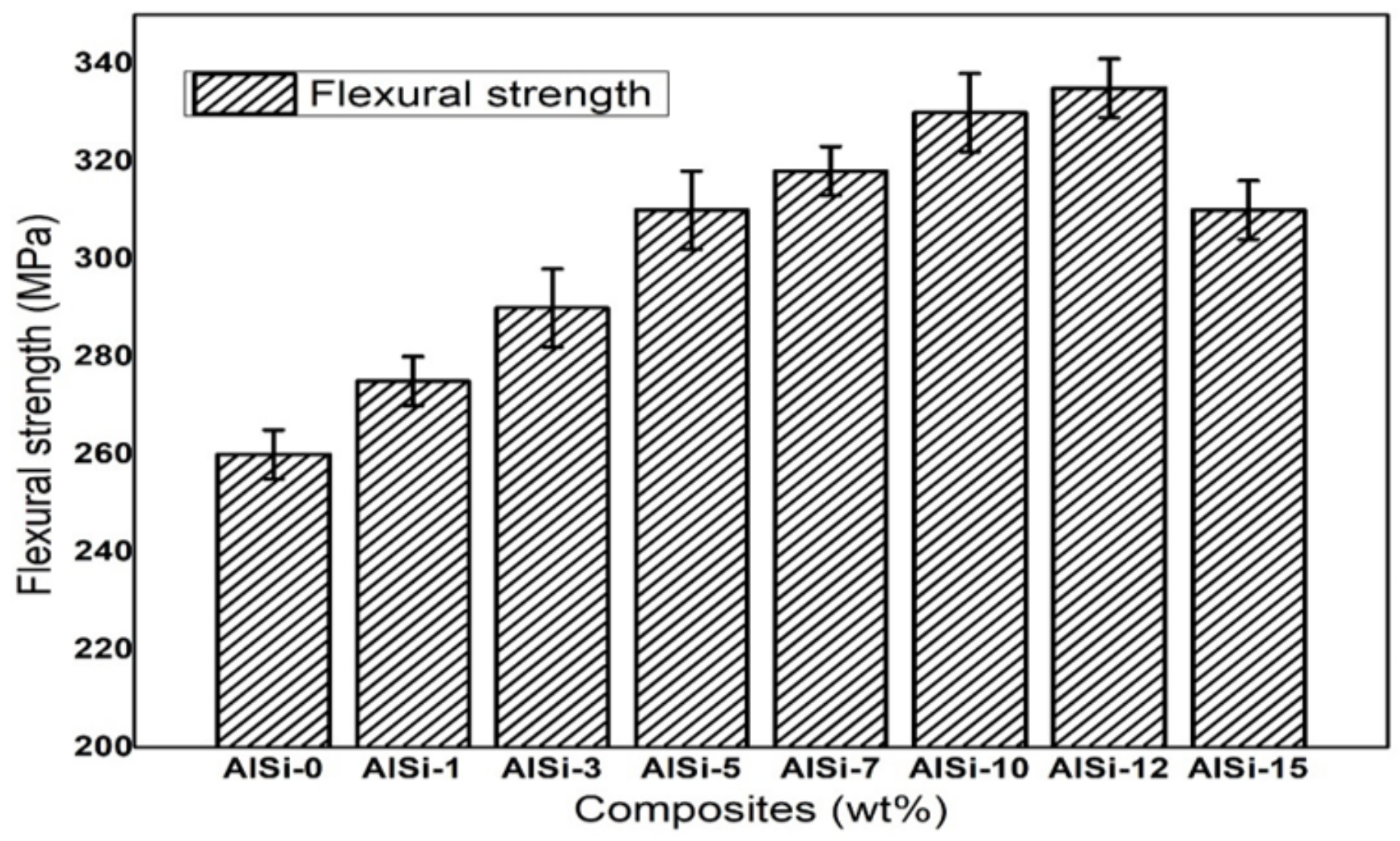

Figure 13

Flexural strength of Al6061-Silica composite 